\title{
Screening and active management reduced perinatal complications more than routine care in gestational diabetes
}

Crowther CA, Hiller JE, Moss JR, et al. Effect of treatment of gestational diabetes mellitus on pregnancy outcomes. N Engl J Med 2005;352:2477-86.

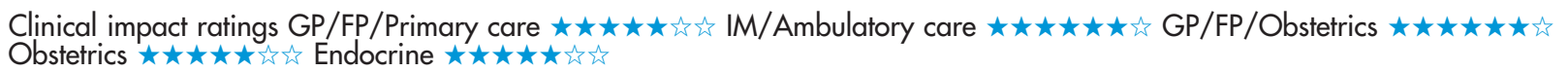
In women with gestational diabetes mellitus (GDM), does a screening and active management intervention reduce
serious perinatal complications more than routine care?

\section{METHODS}

Design: randomised controlled trial (Australian Carbohydrate
Intolerance Study in Pregnant Women [ACHOIS]).
Allocation: \{concealed*\}t.
Blinding: blinded foutcome assessors (except for shoulder
dystocia), data analysts, and monitoring committee\}t.*

\section{MAIN RESULTS}

1030 infants were born. The intervention, relative to routine care, led to fewer perinatal complications, more admissions to the neonatal nursery, more induced labours (table), lower birth weight (3335 v $3482 \mathrm{~g}$, adjusted $\mathrm{p}<0.001$ ), and fewer infants who were large for gestational age $(\mathrm{p}<0.001)$ or had macrosomia $(\mathrm{p}<0.001)$. Groups did not differ for caesarean delivery, components of the composite end point, or other perinatal outcomes.

\section{CONCLUSION}

In women with gestational diabetes, screening and active management reduced perinatal complications more than routine care.

Abstract and commentary also appear in ACP Journal Club.

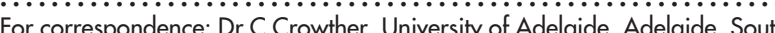
Australia, Australia. caroline.crowther@adelaide.edu.au

Sources of funding: National Health and Medical Research Council Australia and Queen Victoria Hospital Research Foundation.

\section{Commentary}

- inally, the trial by Crowther et al offers high quality evidence to answer the question about the efficacy of treating land therefore screening for) GDM. The approach used in this well designed RCT stands to principally benefit the newborn infant.

I address 5 issues about the current study. Firstly, the proportion of women who initially met the study eligibility criteria but refused to participate was not mentioned. This has implications for the applicability of the results because enrolment may have included only the most compliant or healthy women. Secondly, is the primary composite end point relevant? It seems that this outcome was a realistic reflection of the expected benefits of GDM therapy, in which the rate of infant macrosomia was also reduced from $21-10 \%$. Thirdly, what are the potential harms of dietary counselling with or without insulin therapy? Apart from greater health resource use, the availability of an experienced dietitian and inexpensive glucometer testing, as well as a higher rate of induction of labour, few adverse consequences result from treating GDM. Small, remote hospitals caring for Native women for whom the rate of GDM is high should also be equipped to deal with GDM especially if dietary changes are not possible.' Fourthly, should we screen all pregnant women for GDM based on a $50 \mathrm{~g} \mathrm{GCT}$, or by individual risk factors? For now, the former seems necessary if one applies these study results to clinical practice because $93 \%$ of women were designated as having GDM based on a GCT result. Fifthly, because only $20 \%$ of women in the intervention group received insulin therapy but all received dietary advice, which is more important? Dietary modification should be most emphasised, given that it may reduce risk of macrosomia and birth trauma, and may have long lasting positive effects in terms of reducing the risk of type 2 diabetes, ${ }^{2}$ hypertension, ${ }^{3}$ and, perhaps, cardiovascular disease. $^{4}$

Joel G Ray, MD

St Michael's Hospital, University of Toronto, Toronto, Ontario, Canada

1 Gray-Donald K, Robinson E, Collier A, et al. CMA 2000;163:1247-51.

2 Knowler WC, Barrett-Connor E, Fowler SE, et al. N Engl J Med

2002;346:393-403.

3 Neter JE, Stam BE, Kok FJ, et al. Hypertension 2003;42:878-84.

4 Ray JG. Fetal Matern Med Rev 2004;15:1-16.

SAMI $v$ routine care for gestational diabetes at birth to hospital discharge*

\begin{tabular}{lllll}
\hline $\begin{array}{l}\text { Perinatal and maternal } \\
\text { outcomes }\end{array}$ & SAMI & $\begin{array}{l}\text { Routine } \\
\text { care }\end{array}$ & RRR (95\% CI) & NNT (CI) \\
\hline $\begin{array}{l}\text { Any serious perinatal } \\
\text { complicationt }\end{array}$ & $1 \%$ & $4 \%$ & $68 \%(29$ to 86$)$ & 34 (19 to 98) \\
\hline & & & RRI (CI) & NNH (CI) \\
\hline $\begin{array}{l}\text { Admission to neonatal } \\
\text { nursery }\end{array}$ & $71 \%$ & $61 \%$ & $15 \%(5$ to 26$)$ & 11 (7 to 29) \\
\begin{tabular}{l} 
Induction of labour \\
\hline
\end{tabular} & $39 \%$ & $29 \%$ & $31 \%(10$ to 56$)$ & 11 (7 to 31) \\
\hline
\end{tabular}

${ }^{*} \mathrm{SAMI}=$ screening and active management intervention. Other abbreviations defined in glossary; RRR, RRI, NNT, NNH, and Cl calculated from data in article. †SAMI $=7 / 506$; routine care $=23 / 524$. Deaths $(0 \% v 1 \%)$, shoulder dystocia $(1.4 \% v$ $3 \%)$, bone fracture $(0 \% \vee 0.2 \%)$, and nerve palsy $(0 \vee 0.6 \%)$. 